\title{
Dispense Limited Quantity
}

National Cancer Institute

\section{Source}

National Cancer Institute. Dispense Limited Quantity. NCI Thesaurus. Code C135014.

The dispenser must dispense only a limited quantity of the drug. 